\title{
Una ceremonia secreta. La transposición paródica como procedimiento humorístico en la obra de Fontanarrosa
}

\author{
A Secret Ceremony. Parodic Transposition as \\ Humorous Procedure in Fontanarrosa Works
}

\author{
Dr. Cristian Palacios
}

CONICET - Universidad de Buenos Aires

Doctor en Lingüística por la Universidad de Buenos Aires, Cristian Palacios es investigador en las áreas de análisis del discurso, la semiótica, la lingüística y los estudios del teatro y el arte, con especialización en los discursos cómicos y humorísticos, campo en el cual ha publicado una veintena de artículos. Investigador del Instituto de Lingüística de la Universidad de Buenos Aires, ha publicado El discurso bumoristico. Aproximaciones al estudio del bumor y lo cómico y Hacia una teoría del teatro para niños. Su tesis, aún inédita, se ocupa de los mecanismos ideológicos del humor en la obra de Roberto de Fontanarrosa. Actualmente se desempeña como Investigador del CONICET.

Fecha de recepción: 5 de marzo de 2018

Fecha de aceptación definitiva: 22 de octubre de 2018 


\title{
Resumen
}

El ejercicio de la transposición es una de las operaciones más frecuentes entre los discursos artísticos contemporáneos. En el siguiente trabajo nos ocuparemos de identificar una operación específica a la que denominamos «transposición paródica» a partir del análisis de su uso en la obra del historietista Roberto Fontanarrosa. Este procedimiento, que llega a constituir un género en si mismo, adquiere especial relevancia a la hora de estudiar fenómenos como la transferencia intersemiótica; puesto que al «traducir» determinadas formas en modo paródico, instala una discusión sobre esas formas y la hace ostensible a sus destinatarios.

Palabras clave: Cómico, humor, parodia, transposición, Roberto Fontanarrosa

\begin{abstract}
The practice of transposition is one of the most recurrent operations between contemporary artistic discourses. In the next work we attempt to identify one specific operation that we will call "parodic transposition» from the analysis of its use in the work of the cartoonist Roberto Fontanarrosa. This procedure constitutes in some cases a gender itself and its particularly relevant for the study of intersemiotic translation because translating some figures in a parodic way, setting up a discussion about this figures and make it evident to the audience.
\end{abstract}

Keywords: Comical, Humour, Parody, Transposition, Roberto Fontanarrosa

\section{Cita bibliográfica}

Palacios, C. «Una ceremonia secreta. La transposición paródica como procedimiento humorístico en la obra de Fontanarrosa», en CuCo, Cuadernos de cómic, n.o 11 (2018), pp. 81101. 


\section{Introducción}

El ejercicio de la transposición, entendido aquí como el pasaje de un género, obra o fragmento de obra de un sistema de signos a otro, es una de las operaciones más frecuentes entre los discursos artísticos contemporáneos, tanto entre aquellas expresiones adscriptas a la cultura popular como en el campo de la cultura llamada alta. Dan cuenta de ello numerosos estudios que se han ocupado de esta práctica, precedidos en Argentina por el clásico libro de Oscar Steimberg Semiótica de los medios masivos. El pasaje a los medios de los géneros populares. ${ }^{1}$ No se ha prestado la debida atención, sin embargo, al fenómeno que aquí denominaremos «transposición paródica», entendiendo la parodia como la exhibición deliberada y explícita de ciertos rasgos temáticos, retóricos o enunciativos de un discurso previo, en clave irrisoria. Este procedimiento, que llega a constituir un género en si mismo, adquiere especial relevancia a la hora de estudiar fenómenos como la transferencia intersemiótica; puesto que no solo busca «traducir» determinadas formas de un sistema semiótico a otro, sino que, además, al hacerlo en modo paródico, instala una discusión sobre esas formas y la hace ostensible a sus destinatarios.

Este trabajo buscará dar cuenta de esta operación particular del intercambio discursivo, a partir del análisis de su uso en la obra del historietista, humorista y escritor rosarino Roberto Fontanarrosa. Como es sabido, la obra de Fontanarrosa despliega un mapa de referencias culturales que abarca la literatura testimonial, el género policial en todas sus facetas, la novela de espionaje, la novela rosa, el folletín francés, los relatos de ciencia ficción, la historia, la novela de aventuras, la poesía, la filosofía, la escritura de aforismos y un largo etcétera en el que caben — como ha señalado Daniel Link— nuestras más frecuentes pesadillas, sobre todo aquellas que soñamos despiertos. ${ }^{2}$ Con sus aciertos, fracasos y ocurrencias, esta obra puede leerse enteramente como una gigantesca máquina caníbal, dispuesta a deglutir desde el estricto terreno del humor el entero dominio de la cultura.

${ }^{1}$ Steimberg, O. Semiótica de los medios masivos. El pasaje a los medios de los géneros populares. Buenos Aires, Atuel, 1993. Véanse también Traversa, O. «Carmen, la de las transposiciones», en La piel de la obra. Buenos Aires, Facultad de Filosofía y letras de la UBA, 1995; Grüner, E. El sitio de la mirada. Buenos Aires, Nueva Visión, 2001; BermúdEz, N. «Aproximaciones al fenómeno de la transposición semiótica: lenguajes, dispositivos y géneros», en Estudios Semióticos, n. 4 (2008); Cuadros Contreras, R. Técnica y alteridad: el robot bumanoide en las transposiciones de la literatura al cine. Ibagüe, Universidad de Ibagüe, 2011; SтEIM berg, O. Semióticas. Las semióticas de los géneros, de los estilos, de la transposición. Buenos Aires, Eterna Cadencia, 2013; entre otros.

2 Link, D. «Zapping», en Radar Libros. Suplemento de Página/12, 1 de junio de 2001. Disponible en www. pagina12.com.ar/2001/suple/Libros/01-06/01-06-17/nota5.htm 
De ello viene a dar cuenta uno de sus primeros relatos, «De la comida casera». En él se narra, en modo humorístico, la sobremesa de tres hombres que acaban de comerse a una anciana. En el diálogo que acontece luego, se vislumbra toda una poética. Porque en primer lugar se trata de un plato cuya receta original nadie ha leído. «Era una comida que hacía mi padre que a su vez la aprendió de mi abuelo y así sucesivamente», ${ }^{3}$ afirma Álvarez, el extravagante anfitrión, confirmando que efectivamente, el proceso discursivo en el que se reconoce incluido, no tiene principio ni fin. No tanto por la antigüedad del procedimiento en sí - la antigüedad legendaria de la parodia - sino porque, como todo proceso discursivo, también aquí nos enfrentamos a un juego de remisiones infinitas —- «desde tiempos inmemoriales».

Pero, además, el cuento se ocupa de recordarnos que la maniobra no puede ejecutarse sin más sobre cualquier discurso. Hay que saber seleccionar aquellos que, aunque avejentados, conservan la traza de su antiguo prestigio. Y como a estos, a las ancianas «conviene estudiarlas sin que ellas se den cuenta [...] una anciana de estilo, de raza como se les dice, se reconoce al caminar». Luego de lo cual, se procede al sacrificio: «ese es un capítulo desagradable, quizás molesto, del que se ocupa mi criado [...] donde yo intervengo activamente es en el sazonado y posterior cocción, ahí sí debo reconocer que esa fase me apasiona». Se trata de un rito, casi una ceremonia, «hay en todo un poco de protocolo, incluso de misterio».

Esa justa dosis de protocolo y misterio constituye una de las más extraordinarias definiciones de la parodia a la que va a arribar Fontanarrosa a lo largo de su carrera artística. En las páginas que siguen intentaremos demostrar la productividad que esta operación alcanza entre las páginas de su obra, una suerte de ceremonia secreta en la que asistimos a la deglución general de todo aquello que reconocemos como cultura. Antes, procederemos a delinear algunas de las problemáticas a las que nos enfrentaremos al abordar esta clase de transformaciones, problemáticas que no solo entrañan a la noción misma de parodia — sobre cuyo sentido y proceder se han establecido discusiones ya milenariassino también al concepto de transposición que implica, además, la asimilación por parte de un modo o sistema semiótico de algún otro en el que no encuentra necesariamente correspondencia.

\section{El problema de la traducción intersemiótica}

En su famoso estudio sobre la risa, Henri Bergson, utilizando una figura musical, presentaba el procedimiento de la transposición como una de las operaciones básicas de lo irrisorio consistente en transportar una idea o serie de ideas hacia «un ambiente completamente nuevo» - hacia un nuevo estilo, hacia un nuevo tono- pero conservando la relación que aquellas guardan entre sí». ${ }^{4}$ Por su parte, Freud, en su famoso estudio sobre el chiste, apelaba

${ }_{3}$ Fontanarrosa, R. Los trenes matan a los autos. Buenos Aires, Planeta, 2013, pp. 31-35.

${ }^{4}$ Bergson, H. Le rire. Essai sur la signification du comique. Paris, Éditions Alcan, 2002 [1900, 1924]. 
a la noción de traducción al explicar como aquel transforma un pensamiento serio en un «sinsentido sensato». ${ }^{5}$ Estas dos metáforas del modo de funcionamiento de lo humorístico ponen en evidencia la importancia del problema de las operaciones hipertextuales para toda comprensión profunda del fenómeno de la risa.

Estas operaciones pueden tomar muy diferentes formas que agruparemos aquí en tres modos básicos:

1) Cita inalterada que al ser extraída de un discurso serio cobra, en un marco irrisorio, un sentido nuevo;

2) Traducción/interpretación — en el sentido freudiano- de pensamientos, imágenes, relatos o personajes serios pasados a un contexto cómico o humorístico;

3) Parodia, la exhibición deliberada y explícita de ciertos rasgos temáticos, retóricos, o enunciativos de un discurso previo.

Es en el marco de la parodia que podemos ubicar la operación que aquí llamaremos transposición paródica. Se trata de una transposición — es decir, el pasaje de un sistema de signos a otro de un determinado mensaje o discurso- en clave paródica sobre una obra, fragmento de obra, género o conjunto de géneros. Así, por ejemplo, Los Mitos de Cthulhu de Alberto Breccia es una transposición seria efectuada sobre la serie de cuentos homónima de H.P. Lovecraft, dado que emplea el lenguaje de la historieta para volver a narrar lo que había sido una colección de textos literarios. En cambio, la famosa transposición del poema El Cuervo de Edgar Allan Poe en el primer especial de Halloween de la segunda temporada de Los Simpsons es lo que llamaríamos una transposición paródica, pues agrega a la transformación transpositiva el elemento humorístico característico de aquella serie.

Considerar el asunto de la transposición requiere detenerse momentáneamente en el problema de la traducción intersemiótica que le precede, en tanto implica pensar las posibles correspondencias entre unos y otros modos semióticos. En un artículo de 1969, Emile Benveniste partía de la hipótesis de que los distintos sistemas significantes no eran equivalentes para postular tres diferentes clases de relaciones inter-sistemas:

5 Así la palabra «famillonarmente» — condensación, según se explica luego, de las palabras «familiar»y «millonario»—, utilizada por el personaje de Heine para explicar la manera en que el barón de Rothschild lo ha recibido en su despacho, es reinterpretada — traducida - como la expresión chistosa del siguiente pensamiento: «Rotschild me trató como a uno de los suyos, de manera por entero familiar [familiär] o sea como lo hace un millonario [Millionär]». Freud, S. El chiste y su relación con lo inconsciente. Obras Completas, Tomo viII. Buenos Aires, Amorrortu editores, 1990 [1905]. Según nuestro punto de vista, lo humorístico no se deja traducir de manera tan inmediata como un sinsentido sensato - y parece ser al revés, una sensatez sin sentido- Se diferencia así de lo cómico, bajo cuya agudeza puede, casi siempre, detectarse algún pensamiento «serio». 
1) Relación de engendramiento: «un sistema puede engendrar otro. La lengua usual engendra la formalización lógico-matemática; la escritura ordinaria engendra la escritura estenográfica; el alfabeto normal engendra el alfabeto Braille». ${ }^{6}$

2) Relación de homología: esta relación establece una correlación entre las partes de dos sistemas semióticos. A diferencia de la precedente «no es verificada, sino instaurada en virtud de conexiones que se establecen entre dos sistemas distintos». Benveniste nos da un ejemplo de la poética de Baudelaire: «los perfumes, los colores y los sonidos se responden». ${ }^{7}$

3) Relación de interpretancia: es la que se instituye entre un sistema interpretante y un sistema interpretado. Es la relación fundamental desde el punto de vista de la lengua dado que «reparte los sistemas en sistemas que se articulan, porque manifiestan su propia semiótica, y sistemas que son articulados y cuya semiótica no aparece sino a través de la reja de otro modo de expresión». ${ }^{8}$

Sobre esta última relación, Benveniste establece la preeminencia de la lengua por sobre el resto de los sistemas semióticos, dado que sería la única que poseería la facultad metalingüística que le permite crear un nuevo nivel de enunciación donde se hace posible decir cosas significantes acerca de la significancia. Llegará incluso a afirmar que es «la lengua la que contiene a la sociedad» y no al revés.

El éxito de la tesis apenas permite disimular, sin embargo, el hecho de que se trata de un malentendido cimentado sobre la diferencia que Benveniste establece entre las dos últimas relaciones, otogándole prioridad a la «interpretancia» por sobre la «homología» cuando todo indicaría que la interpretancia es tan solo una forma particular de la homología; aquella que establece una correlación entre las partes de dos sistemas sígnicos sobre la base de «un modelado semiótico». Y eso es porque Benveniste parece desconocer el hecho de que la gran mayoría de los sistemas semióticos pueden explicarse a sí mismos apelando a sus propias posibilidades, tal y como lo hace la lengua. ${ }^{9}$

${ }_{6}^{6}$ Benveniste, E. Problemas de Lingüistica General II. México, Siglo xxi, 2002 [1974], p. 64.

7 Ibid., pp. 64-65.

8 Ibid., p. 65.

9 Dice Benveniste: «la lengua nos ofrece el único modelo de un sistema que sea semiótico a la vez en su estructura formal y en su funcionamiento: 1) Se manifiesta por la enunciación, que alude a una situación dado; hablar es siempre hablar de. 2) Consiste formalmente en unidades distintas, cada una de las cuales es un signo. 3) Es producida y recibida en los mismos valores de referencia entre todos los miembros de una comunidad. 4) Es la única actualización de la comunicación intersubjetiva». Benveniste, E. Op. cit., p. 66. Sin embargo: 1) El desarrollo actual de la teoría de la enunciación nos ha enseñado que no solo la lengua cuando habla, habla siempre de — como afirma Benveniste- También el cine, cuando muestra, muestra que muestra y muestra la forma en que lo muestra. 2) No está tan claro ni que la lengua consista efectivamente en unidades distintas que puedan ser claramente diferenciadas en signos, ni que además sea el único sistema capaz de ser formalizado en unidades. 3) El concepto mismo de «valor» de un signo lingüístico implica que incluso en un corte sincrónico dado no podría haber «el mismo valor de referencia» para todos los miembros de una misma comunidad lingüística. 4) No es en absoluto evidente que la lengua sea «la única 
Lo que nos interesa aquí, en todo caso, es la idea de que toda transformación de una materialidad discursiva en otra implica siempre una actividad productiva por parte de los receptores - $-\mathrm{y}$ nunca meramente reproductiva-, dado que, si bien una traducción nunca dice lo mismo que el original, tampoco el original dice siempre lo mismo, ya sea porque cambian los contextos o por su propio devenir temporal. El sentido no puede concebirse sino como un proceso que nunca se detiene, que está siempre en movimiento y en perpetua transformación.

Tanto en una traducción inter linguas como en el pasaje entre modos semióticos, el productor — consciente o inconscientemente - tiene la posibilidad de acudir a paquetes de recursos previamente estabilizados en un diccionario, existente o no - onomatopeyas como «ibang!» o «iring!» son automáticamente interpretadas como disparo y teléfono, del mismo modo que el término «creepy» es traducido como «escalofriante»-. Pero también puede realizar operaciones no sistematizadas — reemplazar el sonido de un fusil por «icrap!» en lugar de «ibang!», traducir «creepy» como «repulsivo» o intentar producir una nueva oración que sea en si misma escalof riante o una torre, para citar a Chesterton, cuya sola arquitectura sea malvada.

$\mathrm{Al}$ afrontar los problemas de reproducción del original en el ritmo, la sugestión y los niveles sintácticos, la lengua de llegada debe desdoblarse en sí misma hasta el extremo de sacar de sí nuevas posibilidades desconocidas hasta el momento por su propia tradición. Esto significa la renovación de la lengua de llegada en sus niveles sintácticos, sonoros y de sentido. Pero lo mismo puede decirse de la transposición que interpreta (traduce) o traduce (interpreta) «paquetes significantes» de un sistema de signos a otros y al realizarlo debe recurrir a recursos desconocidos en el sistema semiótico que emplea.

\section{Nociones básicas sobre transposición}

Pese a todo lo que antecede, ha de recordarse, sin embargo, que «transposición» $\mathrm{y}$ «traducción intersemiótica» no son términos equivalentes. La transformación de un argumento cinematográfico en una serie televisiva o viceversa no requiere un cambio de modo semiótico aunque sí de soporte, formato, modos de circulación. Cambia el dispositivo, cambia el

actualización de la comunicación intersubjetiva». La gestualidad, por ejemplo, comunica y reparte distancias y cercanías intersujetos sin necesidad de pasar por la lengua. Ciertamente existen sistemas semióticos que, a diferencia de la lengua, no pueden interpretarse a sí mismos; pero se trata de sistemas que han sido previamente engendrados por otros, como es el caso del código morse o los semáforos. La lengua no es el único sistema de signos capaz de desarrollar un metalenguaje complejo. La obra tardía de Levi-Strauss demuestra cómo algunas culturas llamadas primitivas han desarrollado sistemas de clasificación equivalentes a nuestra ciencia moderna a partir de experiencias concretas que no solo no son la lengua, sino que tampoco pueden encuadrarse en cualquiera de los modos semióticas que nuestras culturas se han acostumbrado a percibir como naturales. Lévi-Strauss, C. Mitológicas IV. El hombre desnudo. Buenos Aires, Siglo xxi, 2001 [1971]. La música no puede explicarse a sí misma en términos lingüísticos, pero puede hacerlo en términos musicales. La fuga barroca, por ejemplo, es el ejemplo perfecto del modo en que se puede realmente hacer crítica musical utilizando notas musicales, sin la necesidad de pasar previamente por la lengua. 
sistema sígnico en el que se inscribe, pero no cambia el medio audiovisual en el que ambas se asientan. Las operaciones de traducción intersemiótica, por otro lado, pueden incluir casos no transpositivos como por ejemplo en la translación de la lengua al lenguaje de señas o en la descripción pormenorizada de una imagen visual.

Si bien la transposición no es un fenómeno exclusivamente moderno, la reflexión sobre las operaciones que esta implica se intensifican a medida que nos adentramos en el siglo xx. El desarrollo de las artes del espectáculo, dada la diversidad de materias significantes que ponen en juego, contribuyó en un principio a crear la ilusión de una plenitud de la que carecía, por ejemplo, la literatura.

Muy pronto, sin embargo, fue evidente que el pasaje de un formato semióticamente más simple a otro más complejo no implicaba que se pudieran decir más cosas y ni siquiera mejor —o de forma más compleja-. Este segundo momento va de la mano con la polémica que acompañó al pasaje masivo de las formas tradicionales - literatura dramática y narrativa- al espacio de las artes combinadas.

El malestar ante el pasaje de la literatura asentada en el libro a un «arte combinada» se concretó clásicamente en la denuncia del daño sufrido por una palabra de la que se creyó que podía aspirar a la transparencia, a la remoción de toda materia que se interpusiera entre la lectura social y sus poderes descriptivos o expresivos. Más tarde, se agregó a este malestar la sensación de empobrecimiento generada por la pérdida de la multiplicidad de sentidos. ${ }^{10}$

Esta polémica no estuvo exenta, además, de las resistencias propias de aquellos que conjugaban las tensiones entre literatura y artes del espectáculo con aquellas mucho más antiguas entre «alta cultura» $\mathrm{y}$ «cultura de masas». ${ }^{11}$

Aquello que se muestra en la transposición a los lenguajes híbridos es un tipo particular de producción de sentido de nuestro tiempo que, por ejemplo, en el par cine/literatura desborda ambas prácticas y dice aquello que no es posible decir ni en una ni en otra, recuperando así la condición de irreconciliable que funciona como resistencia para evitar un único sentido del discurso. La transposición sería así el procedimiento por el cual se produce un texto

10 Steimberg, O. (2013). Op. cit., p. 99.

${ }^{11}$ Según el punto de vista de Andreas Huyssen, el modernismo se constituyó en gran medida a partir de una estrategia consciente de exclusión, a partir del miedo a ser contaminado por una cultura de masas crecientemente consumista y opresiva. Esta insistencia del modernismo en la autonomía de la obra de arte y en su radical separación de las esferas de la vida cotidiana, de la política, de las relaciones sociales, de la economía, fue sin embargo cuestionada desde el principio: «De la apropiación de Courbet de la iconografía popular hasta los collages del cubismo, del ataque del naturalismo a l'art pour l'art hasta la inmersión de Brecht en lo vernáculo de la cultura popular, de la explotación consciente de la Madison Avenue por la estrategias pictóricas modernistas hasta el desinhibido aprendizaje del posmodernismo en Las Vegas, ha habido una plétora de movimientos estratégicos orientados a desestabilizar desde adentro la posición alto/bajo». Huyssen, A. Después de la gran división. Modernismo, cultura de masas, posmodernismo. Buenos Aires, Adriana Hidalgo, 2006 [1986], p. 6. Estas tentativas, sin embargo, no solo no han sido perdurables sino que parecen además haber inyectado de una nueva vitalidad a la antigua dicotomía. 
que, partiendo de un orden determinado por su filiación de origen, permite otra filiación determinada no por un único texto, sino por una intertextualidad. Así lo plantea Grüner partiendo de la obra de Walter Benjamin, para quien toda traducción se construye en el espacio de un imposible que debe ser salvado. ${ }^{12}$

También la transposición semiótica reclama la fidelidad del texto destino sobre aquello que parece decir el texto fuente. El procedimiento es doble cuando esa transposición es además paródica, porque requiere del receptor que reconozca cuales son las operaciones semióticas imitadas.

Su estudio implica considerar, por lo tanto, que los cambios de sentido no solo son atribuibles a decisiones individuales, culturales o regionales sino también, y sobre todo, a las diferencias entre sistemas semióticos, materialidades discursivas, lenguajes, dispositivos y géneros. A medida que la operación transpositiva se aleja en tiempo y espacio del texto fuente, se encontrará entonces también modulada por los intereses y representaciones de los nuevos tiempo, espacio y cultura. Cuando, además, este tipo de práctica se encuentre mediada por los gestos propios del humor y lo cómico, nos encontraremos frente a diversas políticas de lecturas que podrían encontrarse fundadas en cualquiera de las dos direcciones que para aquellas modalidades pueden plantearse.

\section{Auto-plagio intersemiótico}

Consideremos, antes de adentrarnos en el estudio de la transposición paródica propiamente dicha un caso singular de transformación, bastante común en Fontanarrosa al que podemos denominar autoplagio inter-semiótico. Se trata de una práctica de transposición sin signo humorístico, entre textos de distintos lenguajes o formatos. Sin signo humorístico, decimos, porque son textos ya de por si irrisorios que al pasar de uno a otro lenguaje no agregan ningún significado cómico. Este ejercicio particular puede también ser pensado a la manera de un lazo invisible que da unidad a una obra que se multiplica en chistes, novelas, historietas y cuentos.

Encontraremos un ensayo temprano de esta operación — pero sin alusión explícita- en el chiste publicado en la tercera página del número 41 de Hortensia (septiembre de 1973) que traslada al formato del chiste gráfico un pasaje del relato «Sobre la podrida pista» incluido en Fontanarrosa se la cuenta: ${ }^{13}$ «Stuart se detuvo frente al escritorio y tomó [...] una postal 12 x 25 donde se veía él mismo junto a Mulligan, ambos con el uniforme de mercenarios. Bajo el pie de Mulligan, relucía un hermoso negro de 97 kilos». ${ }^{14}$

12 Grüner, E. Op. cit.

13 Fontanarrosa, R. Fontanarrosa se la cuenta. Rosario, Encuadre. En este trabajo, sin embargo, citaremos a partir de ahora de la versión de 2013, más accesible al gran público.

${ }^{14}$ Fontanarrosa, R. (2013). Op. cit., p. 113. 


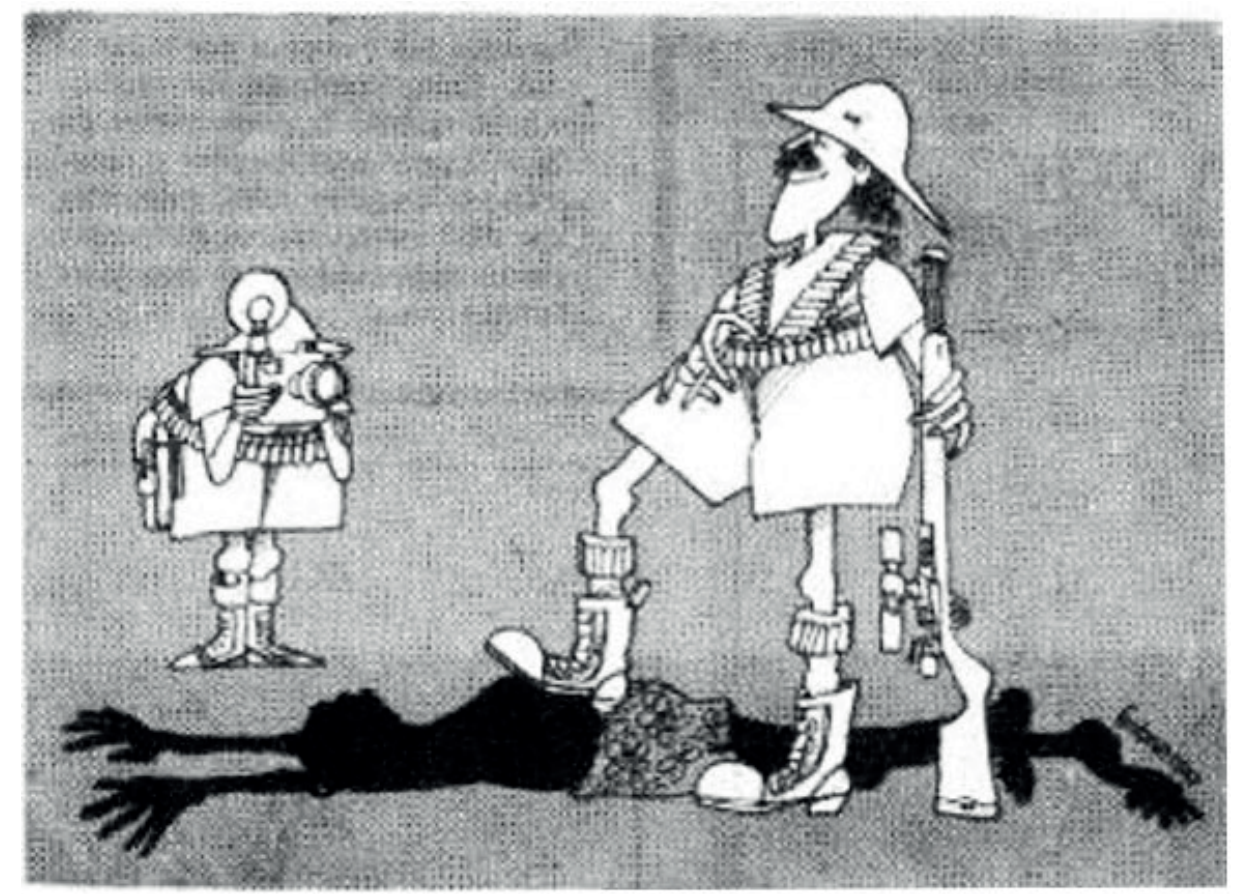

FIG 1. Hortensia, n. 41 (septiembre de 1973).

Como se ve en la FIG. 1, constituye el pasaje del fragmento de un texto mayor hacia un formato que, aunque menor en extensión, debe ser considerado una obra independiente. No se trata aquí de mercenarios, sino de cazadores, lo cual contribuye a autonomizar el sentido: habría que explicar por qué resultaría gracioso y no simplemente sádico que dos mercenarios hayan matado a un negro y adopten la pose de la escena. Mientras que para los cazadores opera una sustitución de sentidos — «seres humanos» por «animales»- que provoca un efecto risible, no por ello menos amargo.

Muchos más explícitas son las transposiciones del cuento a la historieta que muchas veces conservan el título y hasta se anuncian como «versiones» o «versiones libres» de aquellos. Por ejemplo, en la verdadera «puesta en escena» historietística del cuento «Ulpidio Vega» ${ }^{15}$ publicado previamente en El mundo ha vivido equivocado. ${ }^{16}$

La transposición, en este caso, respeta el texto sin quitar o sumar nada. Pero el pasaje de un medio a otro implica en principio fragmentarlo modificando la distribución original de oraciones e imprimiendo por tanto un ritmo nuevo al relato. La clave de lectura de ese ritmo se encuentre quizás en la dedicatoria, presente en la historieta y no en el cuento, a Julian Centeya - pseudónimo de Amleto Enrique Vergiati-, recitador, poeta y letrista de tango, cuya particular manera de decir se adivina entre las pausas que se producen entre uno y otro cuadro (ver FIG. 2).

15 Fontanarrosa, R. «Ulpidio Vega», en Fierro n. ${ }^{\circ}$ 5, enero de 1985.

16 Fontanarrosa, R. El mundo ha vivido equivocado. Buenos Aires, Ediciones De la Flor, 1983. 
Ulpidio Vega, te nombro. / Y de la apagada sombra de tu nombre rescato tu paso tardo por el empedrado desprolijo de Saladillo y la cierta fama de guapo sin doblez que te persiguió sumisa, como la silenciosa y tenaz fidelidad de un perro. /

Quien te vio alguna vez por el Bajo, no te olvida. / De callada mesura, sombrío el porte, mezquinabas palabras como si fueran monedas caras. / Negros los ojos, en la negrura misma que sobre la frente escasa te tiraba encima el ala apenas curva de tu sombrero gris, tan conocido. /

Ulpidio Vega, te nombro. Y de tu nombre exhala un aliento a kerosén barato, a bizcochito, a queso de rallar y vino tinto.

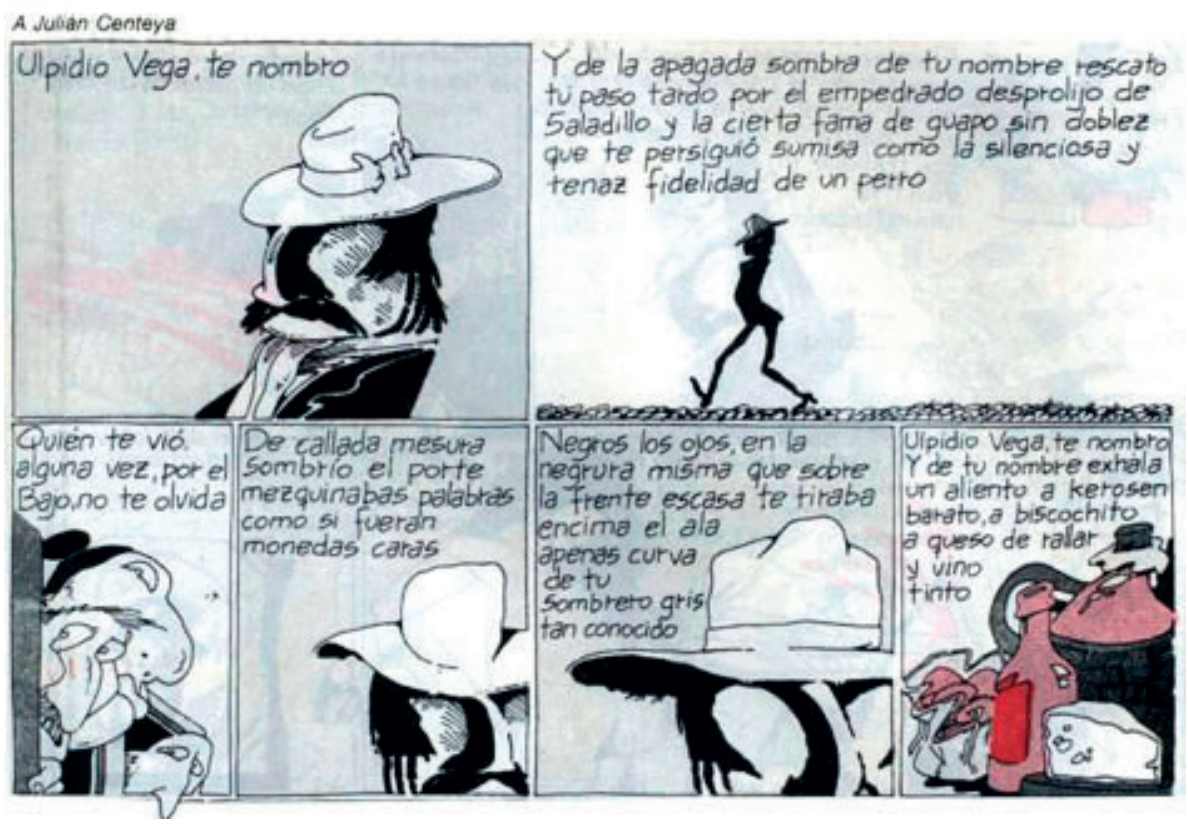

FIG. 2. Fierro, n. 5 (enero de 1985), p. 9.

Se trata, por lo tanto, de la posible interpretación de un texto que en el libro quedaba librado a la musicalidad que cada lector quisiera imponerle. El paso a la historieta parece reclamar en su representación plástica del tiempo la tonalidad de una voz. Que esa voz tenga además nombre propio es una pista que orienta a los lectores hacia un registro anclado en el modo de decir particular del mundo de la poesía lunfarda.

La otra operación es más automática, pero no menos significativa: el reemplazo de las comillas que transcribían el discurso directo libre de los dos Vegas en forma de globos de diálogo. Eso y el hecho de que no haya un solo punto - pero sí comas y signos de exclamación- permite pensar que se está estableciendo aquí un catálogo de equivalencias léxicas entre un sistema semiótico y otro - puntos por espacios entre viñetas, comillas por globos de diálogo.

El resto constituye la ilustración más o menos detallada de aquello que el texto dice, a partir de una serie de decisiones tomadas en pos de la dimensión visual: planos, montajes, diversidad en el ancho de las viñetas, close ups - el de la mano de doña Cata sosteniendo el 
mate-, cambios de luz - la secuencia que se inicia en la imagen de los dos Vegas midiéndose entre las sombras, con gesto inmutable, sosteniendo apenas el roce del ala de sus sombreros y que culmina una viñeta después en la que ambos nariz contra nariz, muestran los dientes, la rabia deformándoles el rostro, «conteniendo las ganas de agarrarse», la imagen fuertemente contrastada, como si el blanco que lo impregna todo fuera el signo de aquella rabia (FIG. 3) - y hasta de color — el salpicón rojo de la sangre, las uñas de la mujer enredada en la cama con Ulpidio, cuya espalda desnuda dibuja una curva perfecta.
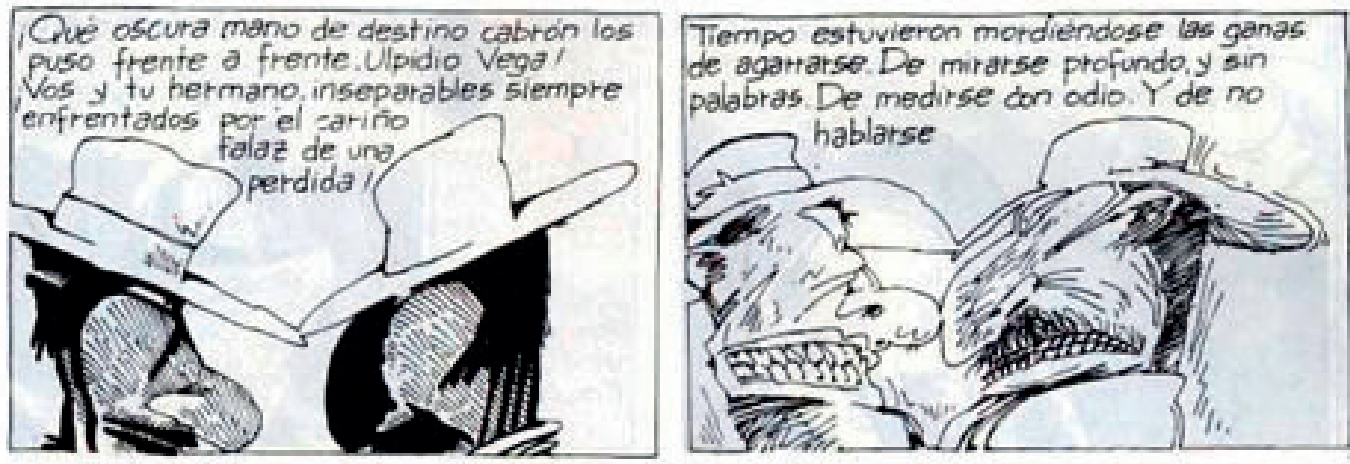

FIG. 3. Fierro, n. 5 (enero de 1985), p. 11.

Pero no hay cambios ni de personajes, ni escenas agregadas, ni viñetas mudas. Todo parece estar al servicio del relato y, quizás por eso, el dibujo, libre de la necesidad de tener que contar algo, alcanza aquí una de los más altos niveles de maestría. ${ }^{17}$

\section{Transposiciones por todas partes. De la gauchesca a Tiburón, pasando por Don Quijote}

Todas estas transposiciones sin signo paródico serán opacadas por el mucho más frecuente procedimiento de la transposición paródica. Esta operación está en la base de las dos obras más reconocidas de Fontanarrosa, Inodoro Pereyra y Boogie el aceitoso, nacida la primera como una transposición paródica de la gauchesca — no solo la literatura gauchesca, sino también el cine, el radioteatro y el folclore - y la segunda como una versión en historieta del género policial negro o hard boiled, más específicamente del cine negro, de quien toma el nombre su protagonista - Boogie el aceitoso es una deformación jocosa de Harry el Sucio,

${ }^{17}$ Otras transposiciones que pueden encuadrarse en la modalidad de auto-plagio intersemiótico se producen por ejemplo entre los cuentos «Edmundo Cachín Medina», «La mayor desgracia», «El récord de Lauven Vogelus», «Los últimos vermicelli» y «Los especialistas» del libro Nada del otro mundo. Fontanarrosa, R. Nada del otro mundo. Buenos Aires, Ediciones de la Flor, 1987; en las historietas "Esa energía sublime», en Fierro n. 6 (febrero de 1985), pp. 9-12, «La desgracia de Juanmiguel Estentóreo», en Fierro n.o 18 (febrero de 1986), pp. 13-16, «El record de Louven Vogelio», en Fierro n. ${ }^{\circ} 7$ (marzo de 1985), pp. 9-12, «Los últimos vermicelli», en Fierro n. ${ }^{\circ} 22$ (junio de 1986), pp. 42-25 y «Los especialistas», en Fierro n. ${ }^{\circ} 13$ (septiembre de 1985), pp. 9-12. 
protagonista de la vigilante movie Dirty Harry, de 1971-. Es además uno de los mecanismos más productivos de la primera etapa de Fontanarrosa como historietista (1972-1984), dado que está presente en prácticamente todas las producciones de esa época, incluyendo la muy política Sperman, el hombre del sexo de hierro - publicada en la revista Fierro entre los números 8 de abril de 1985 y 25 de octubre de 1986-; comenzando por sus transposiciones paródicas de clásicos literarios como La Ilíada o La Odisea, pasando por las cinematográficas, como, por ejemplo, «Bolonki en la torre»-sobre la película The towering inferno (1974) de John Guillerming publicada en Satiricón n. ${ }^{\circ} 26$ de marzo de 1976-; «Segundos afuera... ¡Sensurround!» — sobre el género cine-catástrofe, evoca entre otros filmes Airport 1975 (1975) de Jack Smight y Earthquake (1974) de Mark Robson, publicada en el número 16 de Chaupinela en junio de 1975-; hasta la tardía transposición de la canción de Silvio Rodríguez «La primera mentira» (1969) en la historieta homónima publicada en el número 46 de Fierro (junio de 1988).

Según aquí la concebimos, la parodia es un tipo de transformación deliberada y explícita entre un texto fuente y un texto destino, o bien entre un conjunto de textos asimilados mutuamente por una serie de rasgos comunes que van a intentar ser reproducidos en el texto destino, leídos «en clave irrisoria», a través de la deformación, sustitución, reformulación, condensación o desplazamiento de temas, personajes, estilo, núcleos narrativos, estrategias retóricas, etcétera. Deliberada y explícita porque en principio la parodia aspira a ser reconocida como tal. Aspira a que, de hecho, al volver sobre el texto fuente, reconozcamos aquello que la parodia ha puesto entre paréntesis ya sea con un propósito burlesco - parodia cómi-

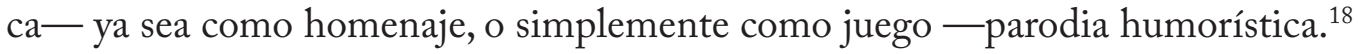

Así, por ejemplo, en la serie conocida como Los Clásicos según Fontanarrosa, el texto fuente se pone en evidencia, ya sea por la transcripción literal del título, como en «Ivanhoe», «Moby Dick», «La Isla del Tesoro» o «La naranja mecánica», ya sea por algún rasgo de alteración mínima como en «Tiburón, qué grande sos» — por Tiburón, sobre la novela homónima de Peter Benchley y la película homónima de Steven Spielberg- ${ }^{19}$ o en «La Cabaña del Tío

${ }^{18}$ El mundo clásico conocía, según Giorgio Agamben, una acepción del término parodia, «que la refería a la esfera de la técnica musical». Ella indicaba «la ruptura del nexo natural entre la música y el lenguaje, la separación paulatina entre el canto y la palabra. O más bien, inversamente, entre la palabra y el canto» Agamben, G. Profanaciones. Buenos Aires, Adriana Hidalgo, 2005, p. 50. De allí la etimología del término: oda, canto; para: «a lo largo de», «al lado»: "parôdein, de ahí parôdia, sería (?) el hecho de cantar de lado, cantar en falsete, o con otra voz, en contracanto - en contrapunto-, o incluso cantar en otro tono: deformar, pues, o transportar una melodía» Genette, G. Palimpsestos. La literatura en segundo grado. Madrid, Taurus, 1989 [1981], p. 24. E1 dato resulta más que significativo cuando consideramos que también Fontanarrosa va a constituir las primeras historias de sus dos personajes más paradigmáticos, tomando como leit motiv temas, imaginarios y modo de decir propios de la música popular; Inodoro Pereyra tomando como referencia lo gauchesco en general pero con fuertes alusiones a la música folclórica- y Boogie el aceitoso — cuyo nombre, más allá de la referencia a Harry el sucio, remite a un conocido ritmo musical norteamericano-. Este mismo procedimiento se extenderá luego a las transposiciones paródicas de La Ilíada y La Odisea, eligiendo esta vez el motivo del tango — superposición cómica, entre otras cosas, de Homero con Homero Manzi.

${ }^{19}$ Fontanarrosa, R. «Tiburón, qué grande sos», en Satiricón n.o 25 (febrero de 1976), pp. 75-77. 
Sam» — sobre La Cabaña del Tío Tom (Uncle Tom's Cabin) de Harriet Beecher Stowe—. ${ }^{20}$ En todos estos ejemplos puede advertirse un propósito lúdico mucho más que burlesco, con la probable excepción de aquellas historietas basadas en blockbusters hollywoodienses, donde la crítica respecto de lo verosímil del relato cinematográfico o el lugar asignado al Star System se hace mucho más acérrima. Paradójicamente, es en estos casos donde la parodia propiamente transpositiva se torna más evidente, dado que las historietas no se limitan a ejercer su transformación irrisoria sobre la trama, sino que hacen su propio comentario sobre el sistema semiótico de procedencia —en este caso, el sistema cinematográfico.

Se pueden resumir en cinco las estrategias por medio de las cuales se establece la transformación transpositiva de signo irrisorio. En primer lugar, por la irrupción de elementos extraños al original, generalmente del orden de lo cotidiano, que contrastan, sobre todo, en los clásicos literarios, tanto con la presunta solemnidad y seriedad del texto fuente como con el contexto sociocultural en el que tiene lugar la trama. En segundo lugar, por la transformación de una serie discursiva en otra de diferente signo — por ejemplo, en «Hamelín tenía un flautista» ${ }^{21}$ las ratas actúan como fanáticas de un recital de rock; o, en «La Ilíada, Partenón y después»,22 al decir que no peleará hasta que no le paguen lo que le deben, Aquiles actúa, en el contexto de la épica griega, como un trabajador en huelga-. En tercer lugar, por la hiperbolización de los procedimientos, argumentos y caracteres del texto fuente. Esta estrategia es más burlesca que lúdica, dado que al llevar al paroxismo algunas de las características propias de personajes y argumentos, establece alguna clase de crítica del original —así en «La cabaña del Tío Sam» ${ }^{23}$ la bondad del viejo esclavo que en la novela es señalizada como una marca de su nobleza, llega al extremo de hacerle decir que los negros no se deben vender ni comprar: «se deben regalar»—. En cuarto lugar, por la inversión de argumentos, procedimientos y caracteres, quizás el menos común de los procedimientos utilizados por Fontanarrosa - en «Más bestia que el hombre», parodia de El extraño caso del Dr. Jekyll y Mr. Hyde de Robert Louis Stevenson, es el hombre quien amenaza a la bestia con su humanidad. «No quiero volver a ser un hombre... no quiero volver a ser un hombre», llora el monstruo al final de la historieta. ${ }^{24}$

Finalmente, podemos señalar una última estrategia transpositiva consistente en reinterpretar el texto fuente de acuerdo con un sentido novedoso nunca exento de ingenio que, sin violentar el orden del original, descubre, por así decirlo, una posibilidad que en este resultaba velada. Esta estrategia, que puede asimilarse a aquella relación que Benveniste había llamado de interpretancia, es particularmente fecunda en «La Odisea no es un bicho» ${ }^{25} \mathrm{O}$

${ }^{20}$ Fontanarrosa, R. «La Cabaña del Tío Sam», en Chaupinela n. 5 (enero de 1975), pp. 23-25.

${ }^{21}$ Fontanarrosa, R. «Hamelín tenía un flautista», en Chaupinela n. 13 (mayo de 1975) , pp. 25-27.

22 Fontanarrosa, R. «La Ilíada, Partenón y después», en Chaupinela n. 10 (marzo de 1975), pp. 23-25.

${ }^{23}$ Fontanarrosa, R. «La cabaña del Tío Sam», en Chaupinela n.o 5 (enero de 1975), pp. 23-25.

${ }^{24}$ Fontanarrosa, R. «Más bestia que el hombre», en Los Humores de Satiricón. Humor Negro n. 2 (junio 1974), pp. 53-54.

25 Fontanarrosa, R. «La Odisea no es un bicho», en Chaupinela n. 11 (abril de 1975), pp. 25-28. 
en «Pabis, Gurus, Laxos \& Praxis», ${ }^{26}$ trasunto esta última de Don Quijote. En la primera, se trastoca el verso homérico en el sentido que los argentinos damos a la palabra verso - «hacer el verso»: engañar, convencer o persuadir por medio de un uso eficaz de la lengua- para arrimar la sospecha de que los relatos de Ulises son un montón de mentiras urdidas para justificar un engaño amoroso - «seguro que estuvo de nuevo en Ogigia con esa loca de la ninfa Calipso» afirma Penélope.

En la segunda la transformación es total. Ya no se trata de un plus de sentido que se agrega a una historia precedente sino exactamente al revés: la historia precedente — el clásico- va a irrumpir en el interior de una historieta de ciencia-ficción que parece respetar hasta ese momento todas las convenciones del género: extraterrestres, naves espaciales y un secreto plan para invadir la tierra que va a ser frustrado por el ingenioso hidalgo de la Mancha en su lucha contra los molinos. Los extraterrestres, amedrentados por esta súbita irrupción de un clásico en un contexto que les es en principio extraño, deciden entonces cancelar su plan de conquista — «iNos ha atacado! ¡Pronto... evaluación de daños..! Nos ha destruido la antena Laxos! Un solo impacto y nos ha destruido nuestra maravillosa antena detectora ¡Son seres poderosísimos! Acelere reparaciones Gurus. Informaremos que es mejor olvidar la conquista».

Al final, Sancho Panza, recogiendo a su maltrecho amo, piensa: «Pobre don Quijote... no sirve para nada» sin poder saber que en realidad este ha detenido la invasión de la Tierra. Todo un alegato a favor de los clásicos cuya inesperada irrupción en un género popular dice mucho sobre el modo en que Fontanarrosa lee la Gran Literatura. La transposición del Quijote, o de cualquier otra obra de gran calibre, al interior de una historieta humorística puede parecer una invasión interplanetaria para aquellos críticos, que impedidos de reconocer en las culturas populares operaciones de producción tan complejas como aquellas de la cultura llamada alta, solo ven aquí un mero divertimento, un pasatiempo sin sustancia, sin comprender el valor político implícito en tales operaciones. A fin de cuentas, aquí también, como en todas partes, se trata de impedir la destrucción del mundo, entre muchas otras pavadas.

\section{5. «E1 Pinino». Un caso de transposición paródica}

Ahora bien, esta fecundidad de un procedimiento cuya utilización en la obra de Fontanarrosa se multiplica por relatos, historietas y chistes, va a tener su límite. Ese límite lo marca, hacia el interior de Inodoro Pereyra, el episodio titulado «E1 Pinino», ${ }^{27}$ publicado en su octavo libro y, algunos meses antes, en el interior del diario Clarín. Ese límite anuncia el fin de la parodia como operación principal del personaje y su mutación de historieta de aventuras en comic strip. A partir de ese momento Inodoro Pereyra verá transcurrir la actualidad

${ }^{26}$ Fontanarrosa, R. «Pabis, Gurus, Laxos \& Praxis», en Satiricón n. 23 (diciembre de 1975), pp. 31-33.

27 Fontanar rosa, R. 20 años con Inodoro Pereyra. Buenos Aires, Ediciones De la Flor, 1998, p. 269. 
entre sus páginas cediendo el lugar de la acción y proponiéndose como mero interlocutor de aquellos personajes que ahora vendrán a su encuentro.

En «El Pinino» tenemos un ejemplo perfecto de transposición paródica con un mínimo de transformación e intención lúdica, sobre un texto fuente que además es explícitamente reconocido, dado que la historieta se cierra con unas «respetuosas disculpas a Osíris Rodríguez Castillo». El texto parodiado es el famoso «Romance del Malevo» del poeta en cuestión. En rigor, el romance le pertenece más al folclore que a la literatura, pues su fama estaba ligada a su interpretación por parte del cantante Argentino Luna. No es extraño que por lo tanto la transformación no opere solo sobre la materia lingüística del poema, sino sobre la performance del recitado. Este plus de sentido se introduce por medio del dibujo, que va a reproducir las inflexiones del rostro y el dramatismo propio del recitador folclórico, con la consabida exageración de los gestos que corresponden a un discurso jocoso. El rostro colérico y enrojecido de Inodoro, los ojos irritados, las venas marcándole el cuello (FIG. 4), trasladan a la viñeta el arrebato pasional propio de aquellos recitados populares.

El texto se acumula en la parte superior de las viñetas sin circunscribirse al globo de diálogo que se encuentra aquí completamente ausente. La necesidad de trasponer la voz entusiasta del recitador folclórico fuerza al dibujante a emplear este procedimiento intermedio entre la onomatopeya - nunca circunscrita y siempre a medio camino entre lo visual y lo lingüístico- y el diálogo — circunscrito por lo general al espacio del globo-. Este recurso será empleado, también, en la transposición de «Ulpidio Vega» a la historieta, que hemos analizado un poco más arriba.

El poema se encuentra comprendido entre dos silencios. El primero nos muestra al personaje como a punto de salir a escena, una mano alzada a la altura del pecho, en el impulso previo al parlamento. En el último, ya con los ojos cerrados, se inclina levemente como para recibir nuestros aplausos. El ritmo describe una curva que se hace más intensa a medida que nos acercamos al clímax trágico de la historia. Los brazos y especialmente la manos describen una gestualidad muy propia de Fontanarrosa. Una gestualidad que además parece formar un mapa autónomo.

La primera operación irrisoria es la sustitución del perro del original por un «gayito enano» cuyo apelativo «El Pinino» evoca graciosamente el de «Malevo» — «No yegaba a levantar, más que una palma del suelo. Lindo porte, güena voz, elegante y pico fino. Por ser un gayito enano, sin tener un nombre a mano, le yamamos: "el Pinino"»- La historieta no respeta la división espacial en versos — recurso común en Fontanarrosa - pero sí la rima. La trama se va construyendo por sustituciones más y más graciosas, con la intromisión aquí y allá de citas explícitas — «y se aquerenció en el rancho» por «Y... ahí se quedó, aquerenciao»; «Eso sí, pa vigilar, no he visto guardián más fiero» por «Eso sí ¿eh? ¡Muy delicao! / ¿Manosiarlo? ¡Ni le cuento!»- En aquel, el perro es un animal «capacitao pa'l trabajo» - ¿Qué animal capacitao / pasl trabajo en campo abierto! / ¡Había que verlo al mentao, / trajinando en un rodeo! / De ser cristiano, ¡clavao / qu'era dotor 
aquel perro!- - En este, el gayito es «prolijo y habelidoso pa los quehaceres domésticos» - "Que ya picaba un salame, que envenenaba unos cueros o apisonaba la tierra con sus patas de tres dedos».

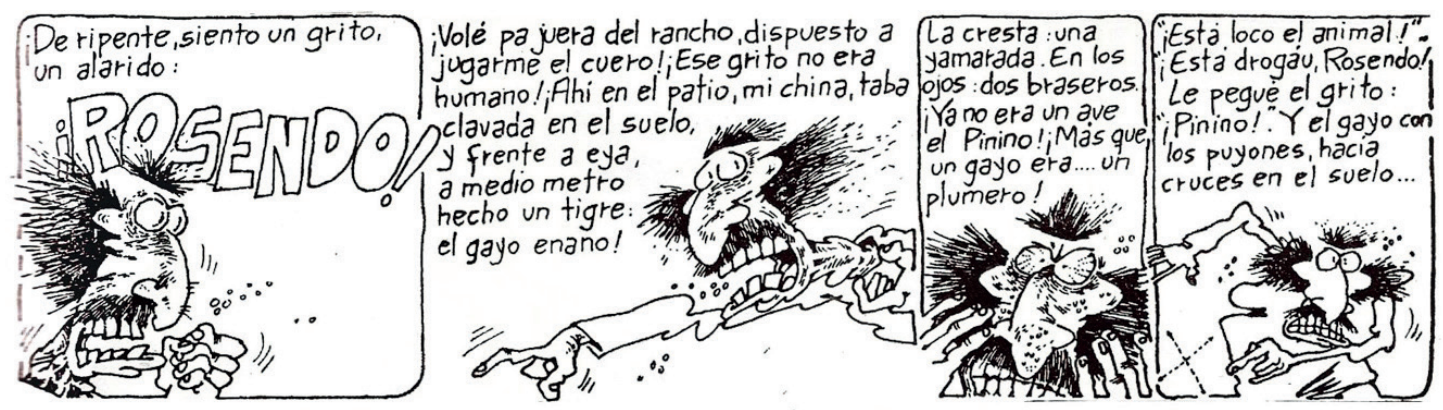

FIG. 4. Fontanarrosa, R. (1998). Op. cit., p. 269.

El punto de mayor tensión llega cuando el gallo, hecho una furia, intenta atacar a su dueño - tal y como le sucedía al malevo-. La escena reproduce casi punto por punto el dramatismo del texto fuente - «Yo estaba echáu en el catre, como chumbándolo al sueño» por «Yo me había echao en el catre / pa' descabezar un sueño»— cuando se escucha el grito — «De ripente siento un grito, un alarido: Rosendo» por «y un redepente, aquel grito / como de terror: “¡Rosendo!” (FIG. 4)—. Aquí se introduce, sin embargo, un nudo narrativo que está ausente en el poema parodiado. En este la rabia del perro es un elemento que no se explica ni necesita ser explicado. Está presupuesto en el sino trágico de su protagonista. En el texto de Fontanarrosa, en cambio, la furia del «Pinino» es producto de un equívoco bastante gracioso: «¿Por qué se habrá puesto así? ¿Comió ortiga esta mañana? Decía mi china yorosa, y aún sostenía en las manos, la cascarita pecosa de un güevo de gayina enana». Se trata, por lo tanto, de la inversión perfecta del poema de Osiris Rodríguez Castillo. Allí el perro es muerto en defensa del hijo del narrador: «No tenía pa' elegir, / hermano! 'tabas enfermo. / Jué po’l, cachorro, ¿sabés? / ¡De nó, no lo hubiera hecho!». Aquí, al revés, es la patrona la que ha aniquilado a los hijos del «Pinino»:

¡Como pa no disgraciarse! Eya no se daba cuenta de esa burla del destino. No había que achacarle el cargo. Meta hacer licor de güevo, mientras tanto, sin quererlo, con la familia 'el Pinino taba haciendo un trago largo.

El final es, a su manera, tan dramático como el original:

«PPerdoná hermano!» — le dije— «iPerdoná, no quise hacerlo!» Yoré hincáu frente a la oya ande giraba, ya muerto. - «iYo sé lo que es un gurí. Puedo saber qué es un güevo!» [luego de lo cual se lo comen] Esa noche, casi sin hambre, lo comimos en puchero. Y a mí hasta me parecía que, desde el plato, con un ala me hacía un gesto, como diciendo bajito: «Yo lo perdono, Rosendo». 
En las últimas viñetas se expanden por hipérbole los últimos versos del original:

Osiris Castillo: Por eso es que, desde entonces, / no me gusta tener perro; / y cuando voy de a caballo, / me parece que lo siento / seguir abajo'el estribo, / ;trote y trote por el tiempo!»; Fontanarrosa: «Por eso desde aquél día, eché las vacas al campo, abrí la puerta 'el chiquero, dejé dir a los cabayos; y ande tenía el gayinero hice un livin-comedor ande, a veces, paso el tiempo. No quiero más animales ¿Pa qué? si cuando los veo, me ricuerdo del «Pinino», de esa tarde y de ese gesto, como diciendo bajito: «...Yo... yo lo perdono, Rosendo».

Este episodio constituye un momento muy particular en la vida del personaje. Completamente instalado en Clarín y en el terreno del discurso periodístico, ya no habrá lugar para la parodia entre sus páginas. La maestría con que Fontanarrosa resuelve un tipo de transposición que había sido ya ensayada por lo menos tres veces ${ }^{28}$ merece sin duda nuestro aplauso. Aquí la transposición paródica opera tanto en el nivel lingüístico como en la operación de transformación que traslada un recitado teatral al lenguaje de la historieta cuidando de evocar tanto los gestos y movimientos de aquellos cantores como los matices y tonos de su voz. A partir de este momento, sin embargo, no solo Inodoro Pereyra, sino la entera obra gráfica de Fontanarrosa ira abandonando el procedimiento descrito hasta emplearlo casi con exclusividad en sus relatos y cuentos —aún seguirá publicando, sin embargo, algunas trasposiciones paródicas en la revista Fierro, hasta fines de los años ochenta.

Cuando Inodoro se incline y se despida, estará también diciendo adiós a un tipo de procedimiento en el que quizás su autor ya no podrá decir nada nuevo.

\section{Conclusiones}

En las páginas precedentes, hemos analizado el uso reiterado del procedimiento de la transposición paródica en la obra de Roberto Fontanarrosa. Se trata de una operación semiótica bastante frecuente en la historieta humorística, que llegó a constituir un género en sí mismo, por ejemplo, en las páginas de la revista $M A D$, tanto en su original norteamericano como en sus versiones vernáculas; o en la revista argentina Hortensia. Esta operación, como dijimos, realiza una transposición semiótica, es decir, un cambio de sistema de signos - de la historieta al cine, de la literatura a la música, de la música a la historieta - desde un punto de vista humorístico. No limita, por lo tanto, los procedimientos paródicos de deformación, sustitución, reformulación, condensación o desplazamiento de temas, personajes, estilo, núcleos narrativos o estrategias retóricas al nivel del enunciado lingüístico o del relato, sino que los aplica también al pasaje entre un modo semiótico y otro.

${ }^{28}$ En la frustrada payada de «Payada con un negro», Fontanarrosa, R. (1998). Op. cit., p. 34 y en Hortensia n. 39 ; en «Recital», Fontanarrosa, R. (1998). Op. cit., p. 43 y en Hortensia n. 41 ; y en "La Telesita», Fontanarrosa, R. (1998). Op. cit., p. 37 y en Hortensia n. 43. 
Que una operación semiótica devenga un género es un hecho discursivo más que frecuente, como lo atestigua el mismo caso de la parodia no-transpositiva. Este devenir género suele implicar, sin embargo, una relativa automatización de los procedimientos que se estancan entonces y pierden su capacidad para decir cosas nuevas de maneras novedosas. La relación de homología, por la cual, según Benveniste, se establecían conexiones creativas entre dos sistemas distintos, deviene una relación de engendramiento, en la cual un sistema engendra a otro sin apertura a la novedad o al cambio discursivo, como suele suceder en el estabilizado sistema de las onomatopeyas que buscan representar visualmente el plano sonoro.

No es el caso de Fontanarrosa, sin embargo, quien antes de la estandarización, suponemos, prefiere abandonar el procedimiento. La gran mayoría de sus historietas construidas a partir de la transposición paródica no se reducen a ser un mero jugueteo lúdico con los textos parodiados, muy por el contrario, casi todas, y más especialmente las series largas como Inodoro Pereyra, Boogie el aceitoso, Sperman: el hombre del sexo de hierro o las Semblanzas deportivas participan antes de un proyecto, es decir, una lectura y una interpretación de aquellas obras, conjunto de obras o géneros a los que se enfrenta. La relación de homología deviene entonces interpretancia. Inodoro relee la gauchesca y se constituye ella misma, una continuación de la misma, una suerte de "gauchesco urbano»; Boogie el aceitoso explora, desde el hard boiled, el imaginario cultural norteamericano, devenido luego global; Sperman se constituye un interpretante particular para comprender, a partir de la historieta de superhéroes, la reactualización de la Guerra Fría en la era Reagan y los clásicos vuelven a leer, desde la cultura popular, las grandes obras de la literatura. 


\section{Bibliografía}

Agamben, G. Profanaciones. Buenos Aires, Adriana Hidalgo, 2005.

Benveniste, E. Problemas de Lingüistica General II. México, Siglo xxi, 2002 [1974].

Bergson, H. Le rire. Essai sur la signification du comique. Paris, Éditions Alcan, 2002 [1900, 1924].

Bermúdez, N. «Aproximaciones al fenómeno de la transposición semiótica: lenguajes, dispositivos y géneros», en Estudios Semióticos, n. o 4 (2008).

Cuadros Contreras, R. Técnica y alteridad: el robot humanoide en las transposiciones de la literatura al cine. Ibagüe, Universidad de Ibagüe, 2011.

Fontanarrosa, R. «Más bestia que el hombre», en Los Humores de Satiricón. Humor Negro n. ${ }^{\circ} 2$ (junio 1974), pp. 53-54.

— «La Cabaña del Tío Sam», en Chaupinela n. 5 (enero de 1975), pp. 23-25.

— «La Ilíada, Partenón y después», en Chaupinela n. 10 (marzo de 1975), pp. 23-25.

— «La Odisea no es un bicho», en Chaupinela n. 11 (abril de 1975), pp. 25-28.

— «Hamelín tenía un flautista», en Chaupinela n. 13 (mayo de 1975) , pp. 25-27.

— «Pabis, Gurus, Laxos \& Praxis», en Satiricón n. 23 (diciembre de 1975), pp. 31-33.

— «Tiburón, qué grande sos», en Satiricón n.o 25 (febrero de 1976), pp. 75-77.

— «Esa energía sublime», en Fierro n. 6 (febrero de 1985), pp. 9-12.

— «El record de Louven Vogelio», en Fierro n. 7 (marzo de 1985), pp. 9-12.

— «Los especialistas», en Fierro n. 13 (septiembre de 1985), pp. 9-12.

— «La desgracia de Juanmiguel Estentóreo», en Fierro n. 18 (febrero de 1986), pp. 13-16.

— «Los últimos vermicelli», en Fierro n. 22 (junio de 1986), pp. 42-25.

- Nada del otro mundo. Buenos Aires, Ediciones de la Flor, 1987.

- 20 años con Inodoro Pereyra. Buenos Aires, Ediciones De la Flor, 1998.

- Fontanarrosa se la cuenta. Rosario, Encuadre

- Los trenes matan a los autos. Buenos Aires, Planeta, 2013. 
Freud, S. El chiste y su relación con lo inconsciente. Obras Completas, Tomo vin. Buenos Aires, Amorrortu editores, 1990 [1905].

Genette, G. Palimpsestos. La literatura en segundo grado. Madrid, Taurus, 1989 [1981].

Grüner, E. El sitio de la mirada. Buenos Aires, Nueva Visión, 2001.

Huyssen, A. Después de la gran división. Modernismo, cultura de masas, posmodernismo. Buenos Aires, Adriana Hidalgo, 2006 [1986].

Lévi-Strauss, C. Mitológicas IV. El hombre desnudo. Buenos Aires, Siglo xxi, 2001 [1971].

Link, D. «Zapping», en Radar Libros. Suplemento de Página/12, 1 de junio de 2001. Disponible en www.pagina12.com.ar/2001/suple/Libros/01-06/01-06-17/nota5.htm

Steimberg, O. Semiótica de los medios masivos. El pasaje a los medios de los géneros populares. Buenos Aires, Atuel, 1993.

- Semióticas. Las semióticas de los géneros, de los estilos, de la transposición. Buenos Aires, Eterna Cadencia, 2013. 